\title{
A Novel Inductor-Based Non-Dissipative Equalizer
}

\author{
Chusheng Lu ${ }^{1,2} \mathbb{D}$, Longyun Kang ${ }^{1,2, *}$, Shubiao Wang ${ }^{1,2}$, Zefeng Wang ${ }^{1,2}$ and Huabing Rao ${ }^{3}$ \\ 1 New Energy Research Center, School of Electric Power, South China University of Technology, \\ Guangzhou 510640, China; lu.chusheng@mail.scut.edu.cn (C.L.); epwangshubiao@mail.scut.edu.cn (S.W.); \\ epzfwang@mail.scut.edu.cn (Z.W.) \\ 2 Guangdong Key Laboratory of Clean Energy Technology, School of Electric Power, South China University \\ of Technology, Guangzhou 510640, China \\ 3 Dong Guan DRN New Energy Co., Ltd., Dong Guan 523000, China; raohb@dgdrn.com \\ * Correspondence: lykang@scut.edu.cn; Tel.: +86-137-2809-8863
}

Received: 13 September 2018; Accepted: 15 October 2018; Published: 18 October 2018

check for updates

\begin{abstract}
Large numbers of non-dissipative equalizers have been proposed for solving the inconsistency problem of lithium battery strings. However, these equalizers face problems such as slow speed or using excessively large numbers of energy storage elements. This paper improved a multiple switch-inductors equalizer (MSIE), and proposed a novel inductor-based non-dissipative equalizer (NIBNDE). A simulation is built to compare the NIBNDE with two other equalizers, which indicated that the NIBNDE can reduce the number of energy storage elements while remaining at a good equalization speed. Experimental results validate the analysis of the simulation and the feasibility of the NIBNDE.
\end{abstract}

Keywords: lithium battery; non-dissipative equalizer; energy storage elements; equalization speed

\section{Introduction}

Currently, lithium batteries are widely used in electric vehicles, hybrid electrical vehicles and stationary storage systems. Due to the limited voltage of a single cell, a lot of cells have to be connected in parallel and in series to provide the required voltage and capacity. However, after multiple charge and discharge cycles, battery cells in the battery pack may suffer from imbalance resulting from aging, internal impedence, manufacturing inconsistencies and differences in operating environment [1]. This imbalance will intensify over time, which greatly degrades the available capacity and battery life, or even leads to overcharge and deep discharge and thus creates potentially dangerous situations $[2,3]$. Battery equalization helps the battery strings alleviate the imbalance, release as much energy as possible and extend battery life. Therefore, the equalization for battery strings needs to be realized.

Battery equalization is a technology for keeping lithium batteries in the same state to avoid deterioration of lithium batteries and safety hazards. It can be categorized into dissipative equalization and non-dissipative equalization. Dissipative equalization appears earlier, so it is more mature, simpler and widely used. However, dissipative equalization consumes energy and generates heat, which reduces the efficiency of the system and increases the difficulty of battery thermal management. The non-dissipative equalization has a higher energy utilization rate and lower heat production than dissipative equalization, but the structure is more complex and the cost is higher [4].

At present, there are a large number of studies on non-dissipative equalization circuits, in which the number of energy storage elements and the speed are two key considerations of the equalization circuit. Non-dissipative equalization circuits can be divided into the following two types: one uses only one energy storage element, such as the single switched-inductor equalizer (SSIE) proposed in [5], as shown in Figure 1, and the equalization circuit in [6]. This kind of topology is simple and low-cost, but it is hard to realize ideal equalization speeds. The other topology has fast equalization speeds, but 
the number of energy storage components used in the equalization circuits are close to the number of batteries, resulting in an oversized circuit and excessive cost. As shown in Figure 2, a parallel architecture equalizer (PAE) based on buck-boost converters for battery strings in [7] is one of the most representative circuits. A systematic comparison has been done in [7], which proves that the PAE has an extraordinarily fast equalization speed. Equalizers for comparison include PAEs based on buck-boost converters, traditional inductor-based adjacent equalizers (IBAE) [8], parallel architecture equalizers based on a multi-wind transformer (PAEBMWT) [9] and double-tiered switched-capacitor equalizers (DTSCE) [10]. The equalization circuits in [1-3,8-19] also suffer from the same problem of oversized circuits and excessive cost. In summary, it is difficult to reduce the number of energy storage elements while maintaining a good equalization speed. This paper improved the MSIE proposed in [11] by using MOSFETs (Metal Oxide Semiconductor Field Effect Transistor) to replace some of the inductors and proposed a novel inductor-based non-dissipative equalizer (NIBNDE). The NIBNDE can significantly reduce the number of energy storage elements and keep a good balancing speed. With the same number of batteries, the NIBNDE uses fewer energy storage elements than the equalization circuits in [1-3,7-19].

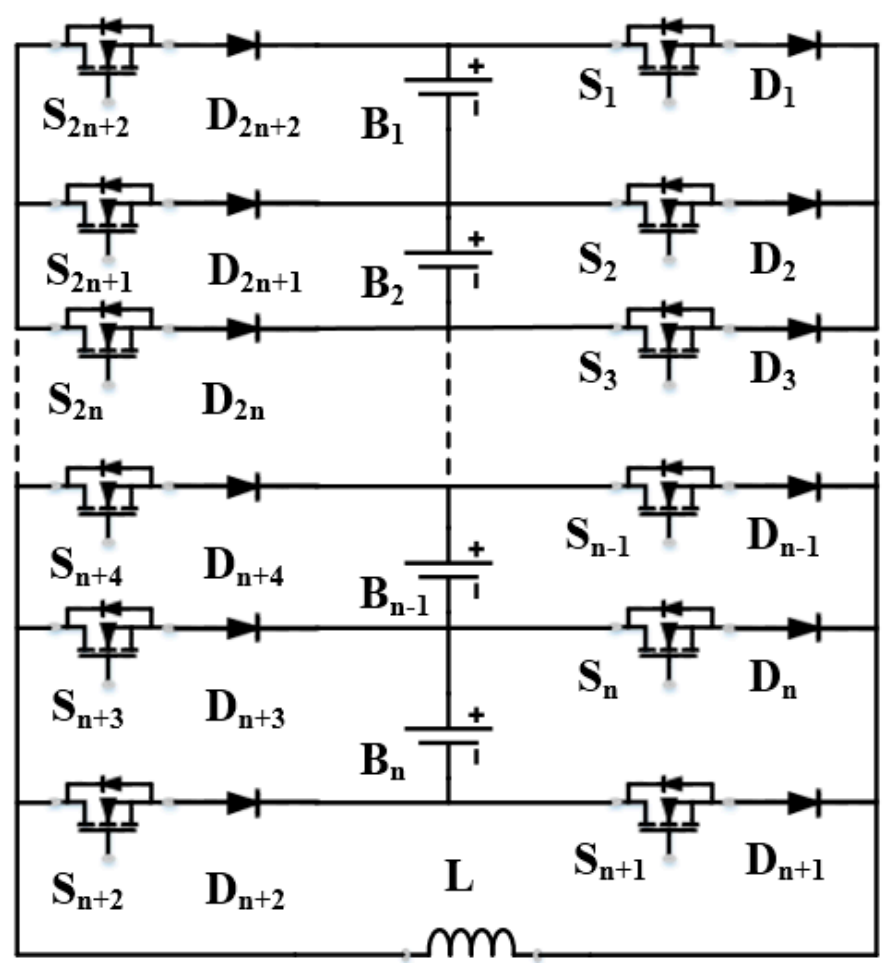

Figure 1. Single switched-inductor equalizer proposed in [5].

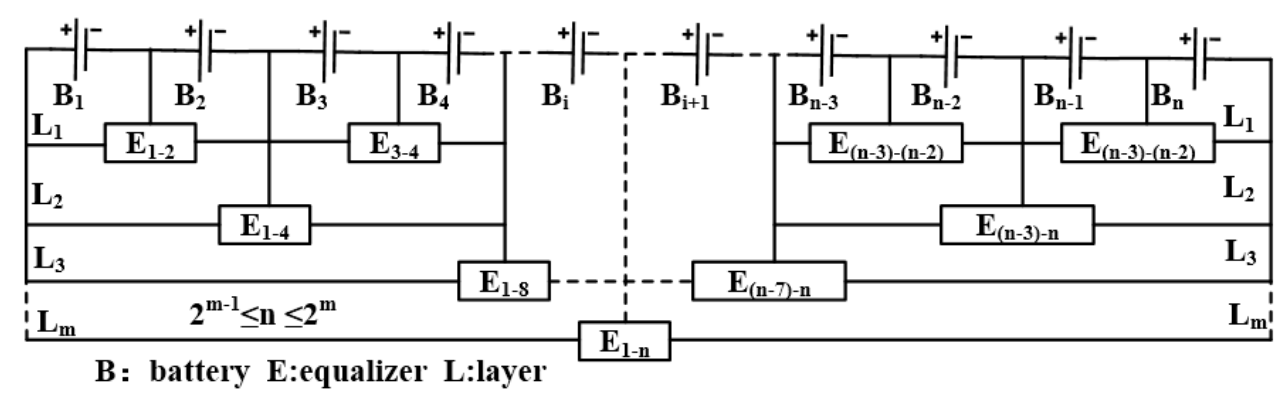

Figure 2. The parallel architecture equalizer proposed in [7]. 
The equalization principle and the key parameters of the NIBNDE are presented in Section 2. Section 3 describes the simulation results and the comparison between NIBNDE, SSIE and PAE. Section 4 compares the experimental results with the simulation results. Section 5 concludes the paper.

\section{Proposed Equalizer Scheme}

\subsection{Structure of the Proposed Equalizer}

The equalization circuit proposed in [11] is shown in Figure 3a. The proposed NIBNDE replaces the even-numbered inductors in [11] with MOSFETs, which can almost reduce half of the inductors. Because the volume of a MOSFET is much smaller than an inductor, the NIBNDE can greatly reduce the volume of the equalization circuit.

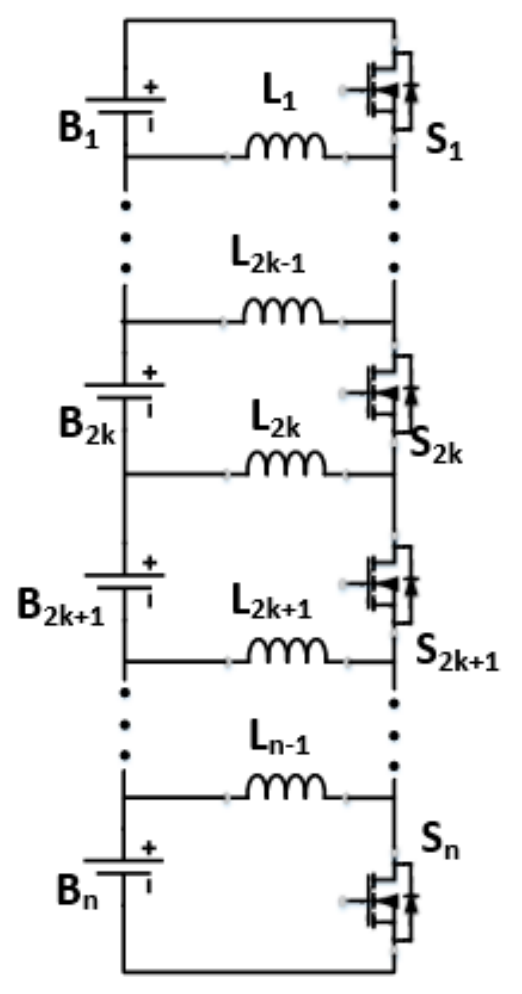

(a)

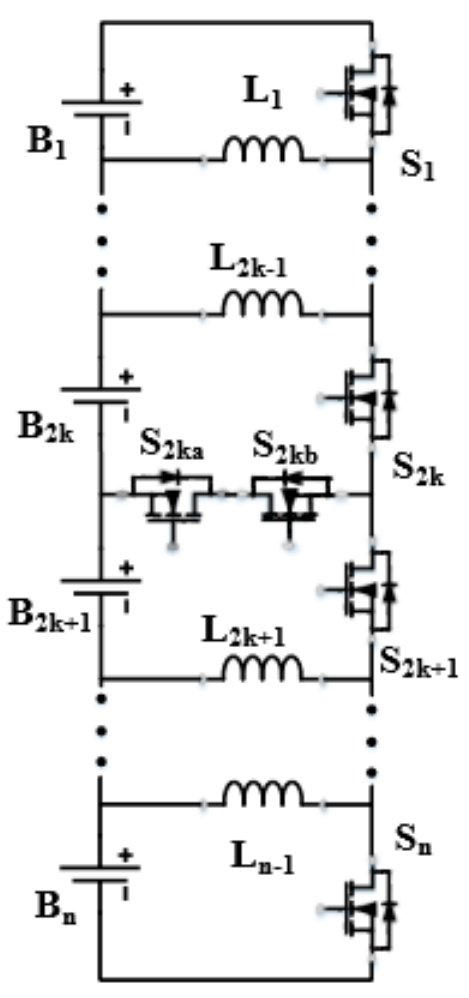

(b)

Figure 3. Structure of equalizer. (a) The multiple switch-inductors equalizer (MSIE). (b) The novel inductor-based non-dissipative equalizer (NIBNDE).

As shown in Figure $3 b$, the number of batteries is assumed to be $n$. If $n$ is an even number, the equalizer consists of $n / 2$ inductors, $(n-2) / 2$ bidirectional MOSFET switches and $n$ MOSFET switches $S_{1}-S_{n}$. The inductors $L_{1}, L_{3}-L_{n-1}$ have odd-numbered subscripts, while the bidirectional switches have even-numbered subscripts, which are respectively named $\left(S_{2 a}, S_{2 b}\right)-\left(S_{(n-2) a}, S_{(n-2) b}\right)$.

If $n$ is an even number, the last set of series MOSFETs is replaced by an inductor to ensure the circuit can operate functionally. Therefore, the required elements are $(n+1) / 2$ inductors, $(n-3) / 2$ bidirectional MOSFET switches and $n$ MOSFET switches $S_{1}-S_{n}$.

\subsection{Equalization Principle}

As shown in Figure 4, the NIBNDE is applied to four series connected batteries for illustrating the equalization principle. The battery $B_{2}$ is assumed to have the highest voltage, $V_{B 2}$, and $B_{1}$ is assumed to have the lowest voltage, $V_{B 1}$. The average voltage $V_{\text {avg }}$ of the four cells is calculated by 
Equation (1). The equalization circuit will be activated when the voltage gap between $V_{B 2}$ and $V_{a v g}$ exceeds the equalization threshold (see Equation (2)). Figure 4 presents the two consecutive stages of the equalization principle [20].

$$
\begin{gathered}
V_{\text {avg }}=\frac{V_{B 1}+V_{B 2}+V_{B 3}+V_{B 4}}{4} \\
V_{B 2}-V_{a v g}<3 \mathrm{mV}
\end{gathered}
$$

Stage 1: Charge $L_{1}$

As shown in Figure 4a, in a pulse-width modulation (PWM) cycle, when $S_{2}$ and $S_{2 b}$ are turned on, cell $B_{2}$ charge inductor $L_{1}, i_{L 1}$ increases [19].

$$
V_{B 2}=R_{o n} i_{L 1}+L \frac{d i_{L 1}}{d t}+V_{D} \quad 0<t \leq t_{o n}
$$

where $R_{o n}$ represents the total loop resistance when $S_{2}$ and $S_{2 b}$ are turned on, $L$ represents the inductance value of $L_{1}, i_{L 1}$ represents the inductor current of $L_{1}, V_{D}$ represents the forward voltage of the body diode of the MOSFET and $t_{o n}$ represents the turn-on time of $S_{2}$ and $S_{2 b}$.

The general solution of Equation (3) is:

$$
i_{L 1}=\frac{V_{B 2}-V_{D}}{R_{o n}}-\frac{V_{B 2}-V_{D}}{R_{o n}} e^{-t \frac{R_{o n}}{L}}=\frac{V_{B 2}-V_{D}}{R_{o n}}\left(1-e^{-t \frac{R_{o n}}{L}}\right) \quad 0<t \leq t_{o n}
$$

When $t=t_{o n}$, the circuit current $i_{L 1}$ reaches the maximum value $i_{p}$, that is:

$$
i_{L 1}=i_{p}=\frac{V_{B 2}-V_{D}}{R_{o n}}\left(1-e^{-t_{o n} \frac{R_{o n}}{L}}\right), \quad t=t_{o n}
$$

Stage 2: Discharge $L_{1}$

As shown in Figure $4 \mathrm{~b}$, when $t>t_{o n}, S_{2}$ and $S_{2 b}$ are turned off, and $L_{1}$ charges $B_{1}$ to transfer energy from cell $B_{2}$ to cell $B_{1}$ :

$$
L \frac{d i_{L 1}}{d t}=V_{B 1}+V_{D}+R_{o f f} i_{L 1} \quad t_{o n}<t \leq t_{d}
$$

The general solution of Equation (6) is:

$$
i_{L 1}=i_{p} e^{-\left(t-t_{o n}\right) \frac{R_{o f f}}{L}}-\frac{V_{B 1}+V_{D}}{R_{o f f}}\left(1-e^{-\left(t-t_{o n}\right) \frac{R_{o f f}}{L}}\right) \quad t_{o n}<t \leq t_{d}
$$

where $R_{o f f}$ represents the total loop resistance when $S_{2}$ and $S_{2 b}$ are turned off and $t_{d}$ represents the moment when the inductor current is reduced to zero [21,22]. 


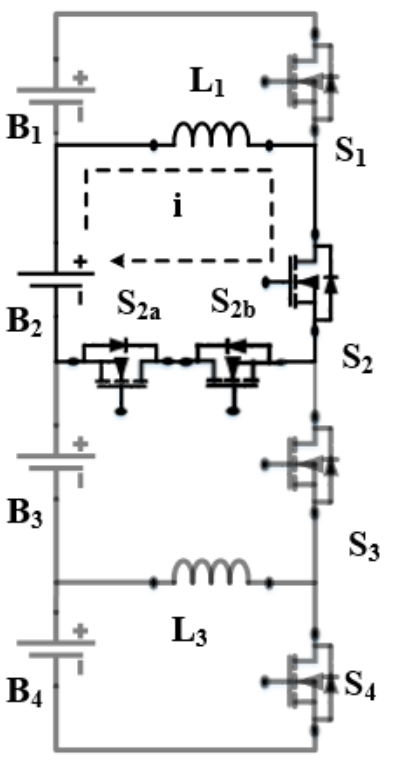

(a)

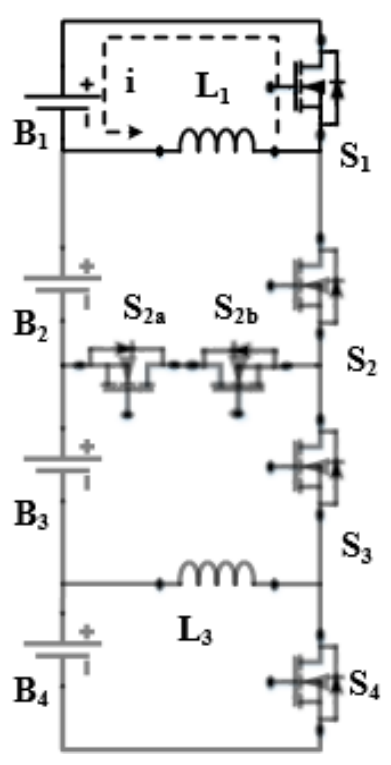

(b)

Figure 4. The equalization principle of the NIBNDE. (a) Charge $L_{1}$. (b) Discharge $L_{1}$.

\subsection{Calculation of the Key Parameters}

In this section, the current and the duty cycle of switching waveforms are analyzed. In Figure $4 \mathrm{~b}$, when $t_{d}<t \leq T$, the circuit current can only flow unidirectionally because the discharge circuit passes through the body diode of $S_{1}$. Therefore, after the inductor $L_{1}$ discharges all the energy, cell $B_{1}$ will not reversely charge the inductor $L_{1}$. T represents the switching period.

Due to the small values of $R_{o n}$ and $R_{o f f}, e^{x}$ is approximately equal to $1+x$. Hence, the above formula about $i_{L 1}$ can also be written as:

$$
\begin{aligned}
& i_{L 1}=\left\{\begin{array}{lr}
\frac{V_{B 2}-V_{D}}{L} t, & 0 \leq t<t_{\text {on }} \\
\frac{V_{B 2}-V_{D}}{L} t_{o n}-\frac{V_{B 1}+V_{D}}{L}\left(t-t_{o n}\right), & t_{\text {on }} \leq t<t_{d} \\
0, & t_{d} \leq t<T
\end{array}\right. \\
& i_{p}=\frac{V_{B 2}-V_{D}}{L} t_{o n}=\frac{\left(V_{B 2}-V_{D}\right) \cdot D \cdot T}{L}
\end{aligned}
$$

In Equation (9), $D$ represents duty cycle. The inductor current has to be reduced to zero within one period. Because $t_{d}$ represents the moment that the inductor current falls to zero, $t_{d}<T$, which means that when $t=T$, the following formula must be satisfied:

$$
\frac{V_{B 2}-V_{D}}{L} t_{o n}-\frac{V_{B 1}+V_{D}}{L}\left(T-t_{o n}\right)<0
$$

Furthermore:

$$
D<\frac{V_{B 1}+V_{D}}{V_{B 2}+V_{B 1}}
$$

\section{Simulation}

In this paper, PSIM (Power Simulation) 9.0 is used for simulation. A number of 1F capacitors are used for substituting batteries to reduce simulation time [1]. The switching frequency is $10 \mathrm{kHz}$ and the inductance is $100 \mu \mathrm{H}$. During simulation, the capacitors, inductors, and switches are considered ideal devices while ignoring the effects of parasitic capacitances and parasitic inductances. Compared to equalization based on state of charge (SOC) inconsistency, equalization based on voltage inconsistency does not require complex algorithms and only needs to collect the cell voltages by voltage sampling 
circuit, making it easier to implement and more commonly adopted [12-14]. This paper use the cell's terminal voltages as the index of inconsistency.

\subsection{Equalization Simulation for SSIE, PAE and NIBNDE with Four Cells}

Since the circuits for comparison are affected by the initial distribution sequences of the batteries, all the distribution sequences will be simulated and compared. The total number of different distribution sequences of the four batteries is $A_{4}^{4}=24$, of which twelve samples are independent. The initial voltages of the four batteries are shown in Table 1, and the equalization threshold is $3 \mathrm{mV}$.

Table 1. The initial cell voltages of four batteries (voltage unit: V).

\begin{tabular}{ccccc}
\hline & A & B & C & D \\
\hline Voltage & 3.98 & 3.96 & 3.92 & 3.88 \\
\hline
\end{tabular}

The circuit diagrams of the three equalizers are shown in Figure 5. Table 2 gives the balancing time of SSIE, PAE and NIBNDE in the twelve independent samples, while Table 3 provides a comprehensive comparison of them. Compared to the SSIE, the proposed NIBNDE requires four less MOSFETs and one more inductor, while reducing the average balancing time by $29.23 \%$. Compared to the PAE, the NIBNDE uses the same MOSFETs and one less inductor. The PAE spends $80.08 \%$ less balancing time than the NIBNDE on average.

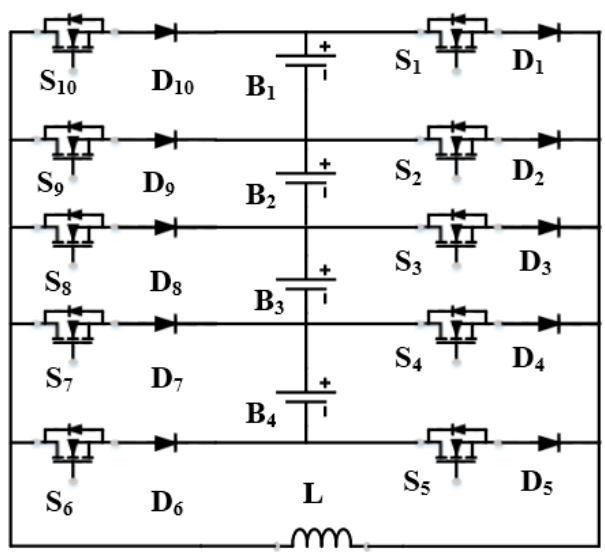

(a)

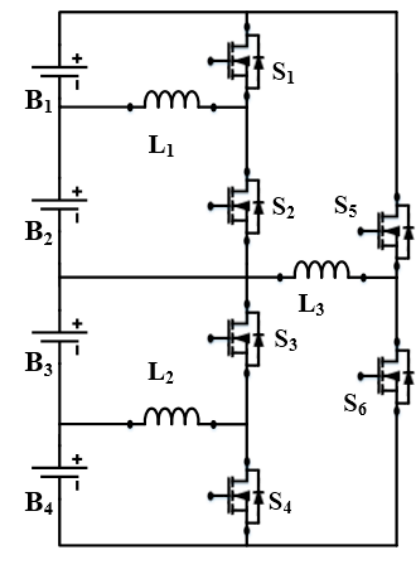

(b)

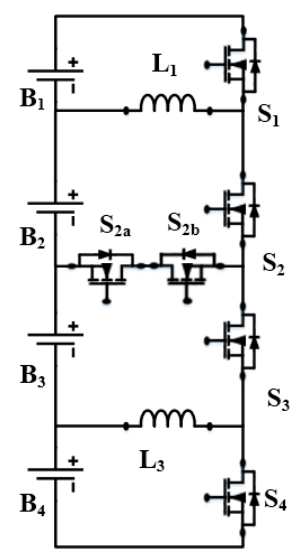

(c)

Figure 5. Circuit diagrams of the single switched-inductor equalizer (SSIE) (a), the parallel architecture equalizer (PAE) (b) and the NIBNDE with four cells (c).

Table 2. The balancing time in different distribution sequences for SSIE, PAE and NIBNDE (time unit: seconds).

\begin{tabular}{cllllllllllll}
\hline & ABCD & ABDC & ACBD & ACDB & ADBC & ADCB & BACD & BADC & BCAD & BDAC & CABD & DABC \\
\hline SSIE & 0.7865 & 0.7867 & 0.7865 & 0.7864 & 0.7875 & 0.7877 & 0.7864 & 0.7864 & 0.7865 & 0.7875 & 0.7864 & 0.7869 \\
PAE & 0.059 & 0.059 & 0.1216 & 0.1214 & 0.1525 & 0.1522 & 0.059 & 0.059 & 0.1525 & 0.1213 & 0.1209 & 0.1525 \\
NIBNDE & 0.6355 & 0.6916 & 0.2775 & 0.564 & 0.6905 & 0.5651 & 0.6985 & 0.7543 & 0.29 & 0.7542 & 0.4707 & 0.29 \\
\hline
\end{tabular}

Table 3. The comparison between SSIE, PAE and NIBNDE in four cells battery string (G: Good; M: Marginal; P: Poor).

\begin{tabular}{cccccc}
\hline & Expected Time (s) & Cell Number & MOSFET & Inductor & Control Complexity \\
\hline SSIE & 0.7868 & 4 & 10 & 1 & $\mathrm{M}$ \\
PAE & 0.1109 & 4 & 6 & 3 & $\mathrm{G}$ \\
NIBNDE & 0.5568 & 4 & 6 & 2 & $\mathrm{M}$ \\
\hline
\end{tabular}


In summary, although the SSIE uses only one inductor, the equalization time and the number of MOSFETs for the NIBNDE are both less than the SSIE. The equalization speed of the PAE is faster than the NIBNDE, but the NIBNDE uses one less inductor.

\subsection{Equalization Simulation for SSIE, PAE and NIBNDE with Six Cells}

As shown in Figure 6, SSIE, PAE and NIBNDE are applied to six cells in order to compare the balancing speed between them. The number of different distribution sequences of the six batteries is $A_{6}^{6}=720$, of which three hundred and sixty samples are independent. In this paper, we chose fifty random samples to simulate and calculate the average balancing time. The initial voltages of the six batteries are shown in Table 4, and the equalization threshold is $3 \mathrm{mV}$. Figure 6 shows the circuit diagrams of SSIE, PAE and NIBNDE with six cells.

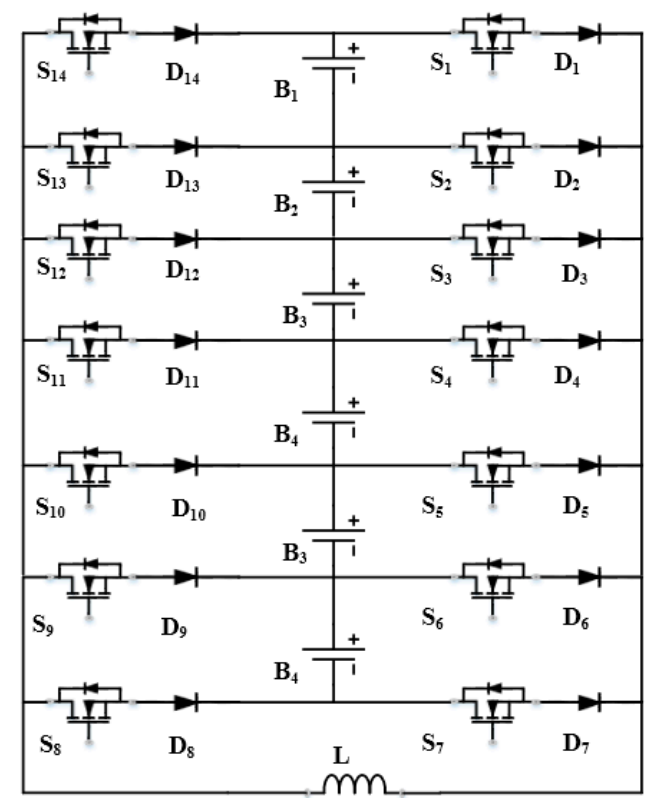

(a)

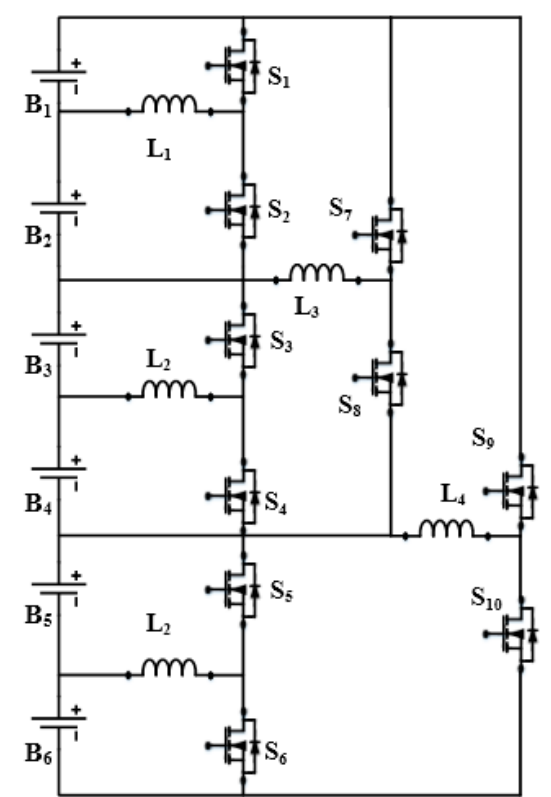

(b)

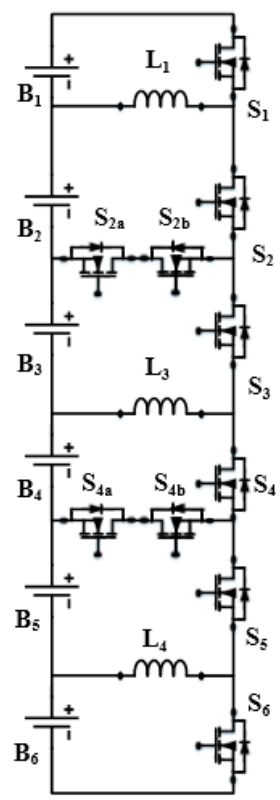

(c)

Figure 6. Circuit diagrams of SSIE (a), PAE (b) and NIBNDE (c) with six cells.

Table 4. The initial cell voltages of the six cells (voltage unit: V).

\begin{tabular}{ccccccc}
\hline & A & B & C & D & E & F \\
\hline Voltage & 3.98 & 3.96 & 3.94 & 3.92 & 3.90 & 3.88 \\
\hline
\end{tabular}

Figure 7 presents the simulation waveforms in SSIE, PAE and NIBNDE with the distribution sequences of ABCDEF. VB $x(x=1-6)$ represents the voltage of $B_{x}$. Table 5 gives a comparison of the data. Compared to the SSIE, the proposed NIBNDE requires four less MOSFETs and two more inductors, while reducing the average balancing time by $34.52 \%$. Compared to the PAE, the NIBNDE uses the same MOSFETs and two less inductors. The balancing time of the PAE is $75.19 \%$ less than the NIBNDE. 


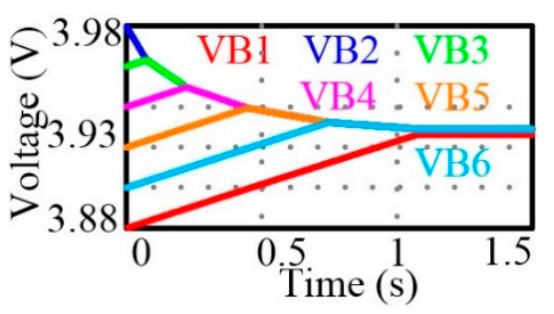

(a)

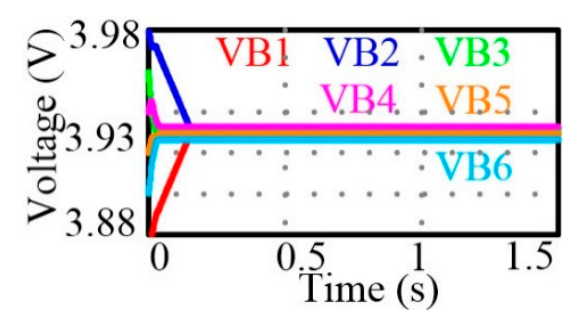

(b)

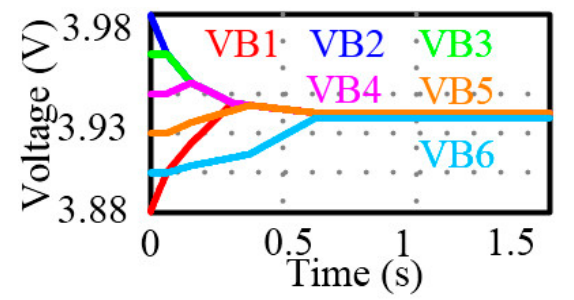

(c)

Figure 7. Six cell voltage trajectories in simulation. (a) The SSIE. (b) The PAE. (c) The NIBNDE.

In summary, although the SSIE uses only one inductor, the equalization time and the number of MOSFETs for the NIBNDE are both less than the SSIE. The equalization speed of the PAE is faster than the NIBNDE, but they use the same number of MOSFETs and the NIBNDE uses two less inductors than the PAE.

Table 5. The comparison between SSIE, PAE and NIBNDE in a six cell battery string (G: Good; M: Marginal; P: Poor).

\begin{tabular}{cccccc}
\hline & Expected Time (s) & Cell Number & MOSFET & Inductor & Control Complexity \\
\hline SSIE & 0.9983 & 6 & 14 & 1 & $\mathrm{M}$ \\
PAE & 0.1622 & 6 & 10 & 5 & $\mathrm{G}$ \\
NIBNDE & 0.6537 & 6 & 10 & 3 & $\mathrm{G}$ \\
\hline
\end{tabular}

\subsection{Equalization Simulation for SSIE, PAE and NIBNDE with Sixteen Cells}

SSIE, PAE and NIBNDE are applied to sixteen cells in this section. The number of different distribution sequences of the sixteen batteries is over $2 \times 10^{13}$, of which more than $1 \times 10^{13}$ samples are independent. In this paper, we chose one hundred random samples to simulate. The initial voltages of the sixteen batteries are shown in Table 6, and the equalization threshold is $3 \mathrm{mV}$.

Table 6. The initial cell voltages of sixteen cells (voltage unit: V).

\begin{tabular}{ccccccccc}
\hline & A & B & C & D & E & F & G & H \\
\hline Voltage & 3.98 & 3.96 & 3.94 & 3.92 & 3.90 & 3.88 & 3.86 & 3.84 \\
\hline & I & J & K & L & M & N & O & P \\
\hline Voltage & 3.82 & 3.8 & 3.78 & 3.76 & 3.74 & 3.72 & 3.7 & 3.68 \\
\hline
\end{tabular}

Figure 8 presents the simulation waveforms in SSIE, PAE and NIBNDE with the distribution sequences of DPCAEFGHIJKLMBON, in which $\operatorname{VB} x(x=1-16)$ represents the voltage of $B_{x}$. Table 7 shows the comparison of the data. Compared to the SSIE, the NIBNDE reduces the equalization time by $22.4 \%$ while using seven more inductors; the PAE reduces the equalization time by $88.8 \%$ while using fourteen more inductors. At the cost of increasing the required inductors, the PAE is more efficient than the NIBNDE in increasing the equalization speed. However, when it is necessary to increase the equalization speed while not expecting to excessively increase the required inductors, 
the NIBNDE proposed in this paper can be considered. That is to say, when considering both the equalization speed and the number of inductors, this paper provides another choice for selecting an equalization circuit.

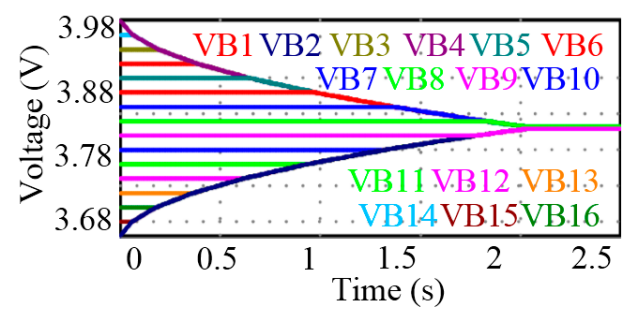

(a)

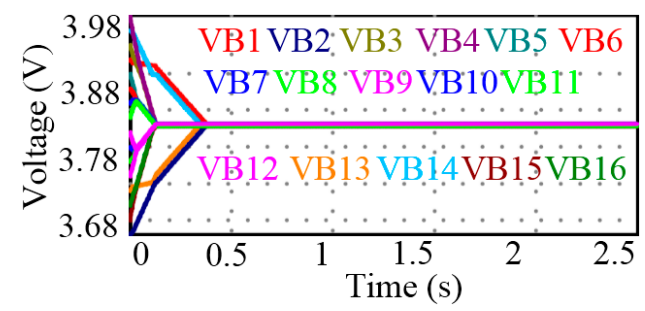

(b)

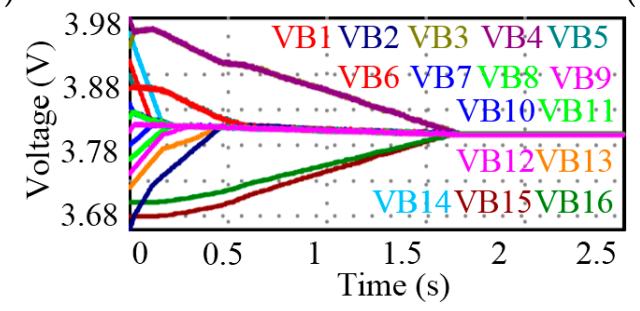

(c)

Figure 8. Sixteen cell voltage trajectories in simulation (a) The SSIE. (b) The PAE. (c) The NIBNDE.

Table 7. The comparison between SSIE, PAE and NIBNDE in a sixteen cell battery string (G: Good; M: Marginal; P: Poor).

\begin{tabular}{cccccc}
\hline & Expected Time (s) & Cell Number & MOSFET & Inductor & Control Complexity \\
\hline SSIE & 2.0441 & 16 & 34 & 1 & $\mathrm{M}$ \\
PAE & 0.2283 & 16 & 30 & 15 & $\mathrm{G}$ \\
NIBNDE & 1.5862 & 16 & 30 & 8 & $\mathrm{M}$ \\
\hline
\end{tabular}

\subsection{Comparison for PAE and NIBNDE with $n$ Cells}

Table 8 shows that the NIBNDE has one less MOSFET than the PAE when the number of batteries is odd and the same number of MOSFETs when the number is even.

Furthermore, the difference in the amount of inductance between PAE and NIBNDE increases with the number of batteries, which can be seen from Equations (12) and (13):

$$
\begin{aligned}
& \mathrm{e}_{\mathrm{o} d d}=\frac{n-3}{2} \\
& \mathrm{e}_{\text {even }}=\frac{n-2}{2}
\end{aligned}
$$

where $\mathrm{e}_{\mathrm{o} d d}$ represents the difference in the number of inductances between PAE and NIBNDE when the number of batteries is odd. $e_{\text {even }}$ represents the difference in the number of inductances between PAE and NIBNDE when the number of batteries is even.

The price of one inductor is 3 yuan and the volume of one inductor is $0.66 \mathrm{~cm}^{3}$. When there are 16 cells, compared to the PAE, the NIBNDE uses seven less inductors, so it costs 21 yuan less and reduces the volume by $4.62 \mathrm{~cm}^{3}$, but the equalization time of the NIBNDE is about seven times that of the PAE's equalization time. In this case, the PAE is better than the NIBNDE. However, when the number of cells is 128, the NIBNDE uses 64 inductors less than the PAE, so it costs 192 yuan less and reduces the volume by $42.24 \mathrm{~cm}^{3}$. In summary, when there are a large number of cells, the cost of the inductors and the volume of the equalization circuit are as important as the equalization speed, so both the NIBNDE and the PAE have their own advantages. 
Table 8. The comparison between SSIE, PAE and NIBNDE in an $n$ cell battery string $(n \geq 2)$.

\begin{tabular}{cccc}
\hline & Cell Number & MOSFET & Inductor \\
\hline SSIE & $n$ & $2 n+2$ & 1 \\
PAE & $n$ & $2 n-2$ & $N-1$ \\
NIBNDE & $n$ & $2 n-2$ (when $n$ is even) & $n / 2$ (when $n$ is even) \\
& & $2 n-3$ (when $n$ is odd) & $(n+1) / 2$ (when $n$ is odd) \\
\hline
\end{tabular}

\section{Experimental Results}

Experiments have been carried out to verify the equalization performance of the NIBNDE. Table 9 gives the initial cell voltages. An equalization prototype with four 2.2 Ah Samsung lithium batteries is built and the parameters are summarized in Table 10, which $\mathrm{R}_{\mathrm{DS}(\text { on })}$ represents the on-resistance of MOSFET. This section compares the simulation with the experiment. The frequency, the equalization threshold and the initial voltages of the batteries in the simulation are the same as the experiment.

Table 9. The initial cell voltages of four batteries (voltage unit: V).

\begin{tabular}{ccccc}
\hline & A & B & C & D \\
\hline Voltage & 3.9264 & 3.9859 & 3.9769 & 3.963 \\
\hline
\end{tabular}

Table 10. Component values used for the equalizer.

\begin{tabular}{|c|c|c|c|c|}
\hline Parameters & & & Value & \\
\hline Battery string & Samsung lithium battery & $B_{1}-B_{4}$ & $2.2 \mathrm{Ah}$ & - \\
\hline Equalizer & MOSFET & $S_{1}-S_{4}, S_{2 a}, S_{2 b}$ & IRF3205PBF & $\mathrm{R}_{\mathrm{DS}(\text { on })}<0.008 \Omega$ \\
\hline - & Inductor & $L_{1}, L_{3}$ & $100.8 \mu \mathrm{H}, 100.1 \mu \mathrm{H}$ & $\begin{array}{l}\mathrm{R}<0.0752 \Omega \\
\mathrm{R}<0.0547 \Omega\end{array}$ \\
\hline
\end{tabular}

Figure 9 shows the four cells' voltage waveforms in the equalization process. Figure 10 presents the separate figures for the transient voltages of cells A, B, C, and D. Figure 11 shows a comparison of the four cells' voltages before and after equalization. The initial voltage gap shown in Table 9 is $59.5 \mathrm{mV}$, and it decreases to $4 \mathrm{mV}$ at about $34 \mathrm{~min} 53 \mathrm{~s}$, so the equalization accuracy of the NIBNDE is excellent.

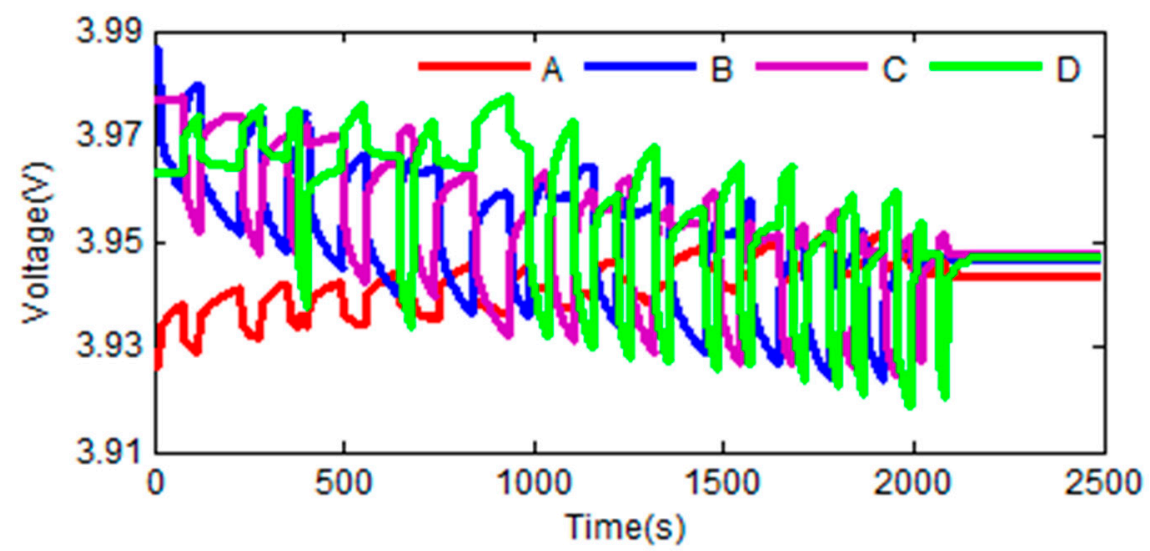

Figure 9. Four cells' voltage waveforms in the equalization process. 


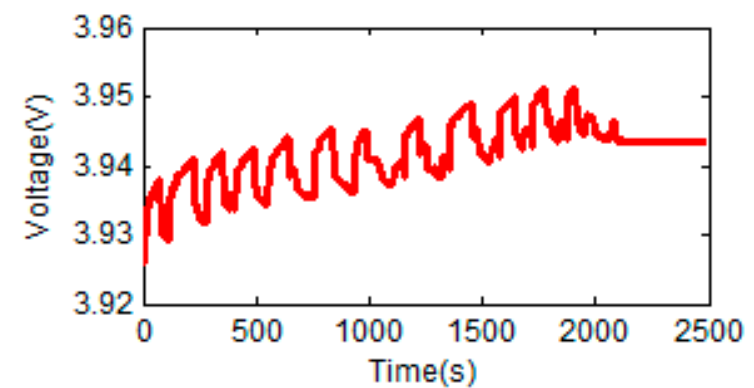

(a)

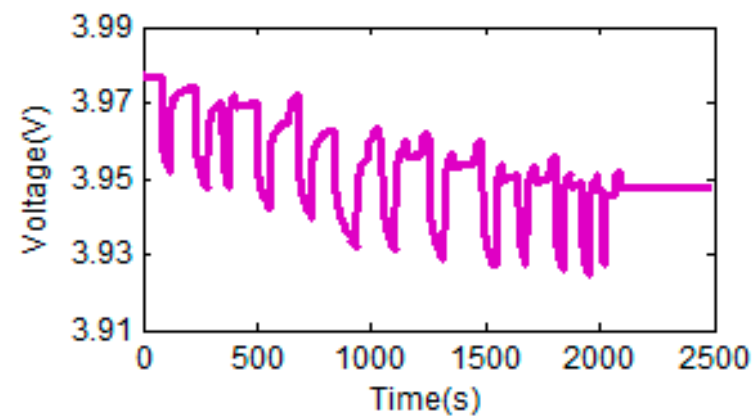

(c)

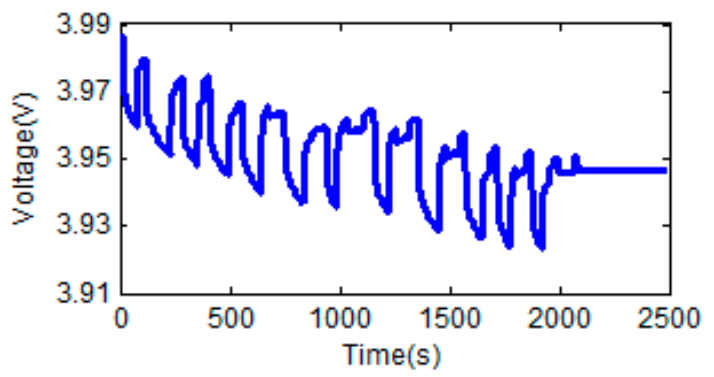

(b)

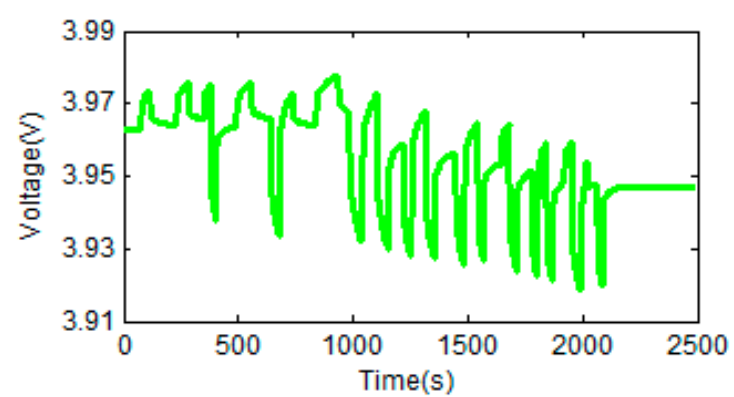

(d)

Figure 10. The cells' voltage waveforms in the equalization process for A, B, C and D (a) A. (b) B. (c) C. (d) D.

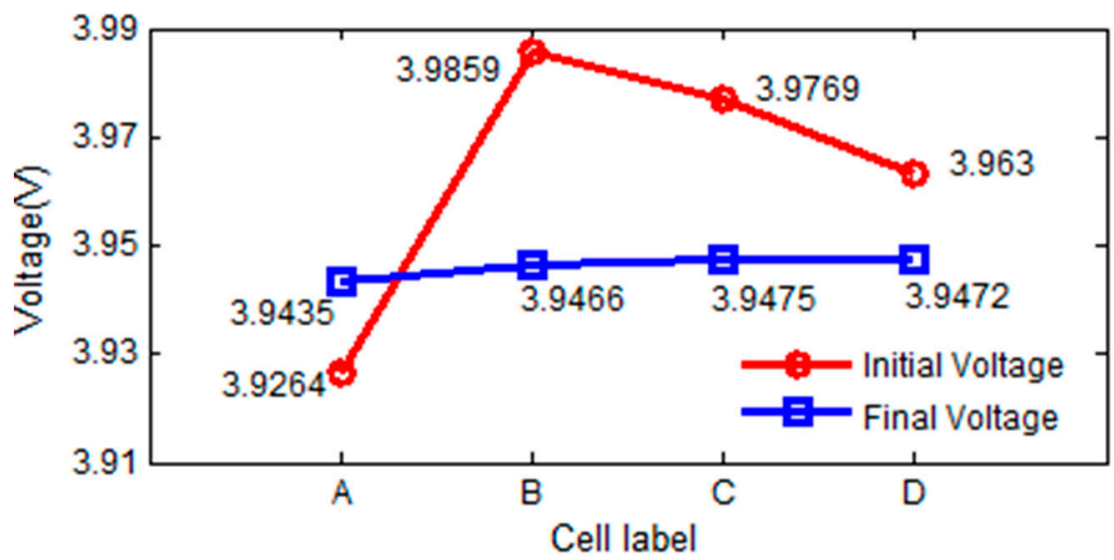

Figure 11. Voltages of the four cells before and after equalization.

As shown in Figure 12, the initial voltage gap $(59.5 \mathrm{mV})$ decreases to $4 \mathrm{mV}$ at about $0.2139 \mathrm{~s}$ in the simulation. In the experiment, the batteries have internal resistance, the inductors have resistance and magnetic leakage, the MOSFETs have on-resistance, the voltage detection of the battery has errors, etc. As a result, the average voltage in the experiment is lower than the simulation result.

As shown in Figure 13, the peak value of the inductor current $i_{L 1}$ in the experiment is about $1.51 \mathrm{~A}, 4.79 \%$ lower than the simulation result (1.586 A). Considering the resistance of the experimental circuit and the components used in the experiment are not ideal, the current error is small enough. In summary, the accuracy of the equalization is excellent and experimental results agree with the analysis in Section 2.3. 


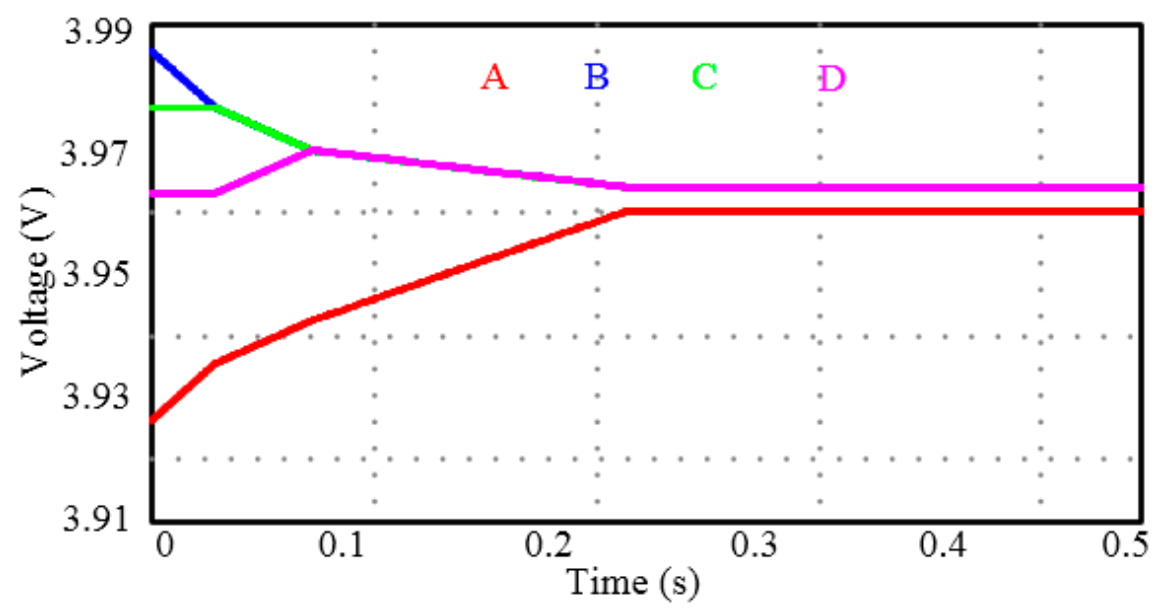

Figure 12. Four cells' voltage trajectories in simulation.

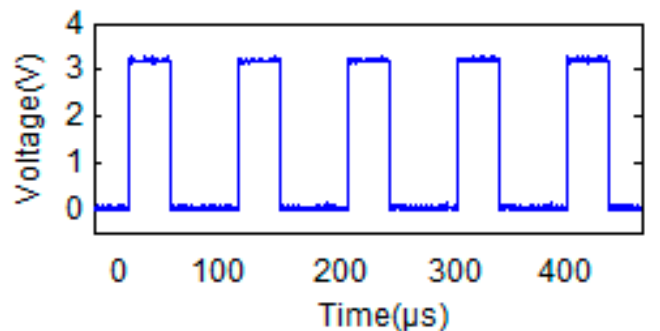

(a)

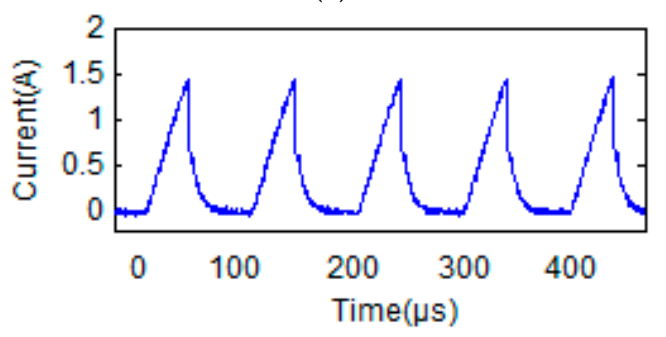

(c)

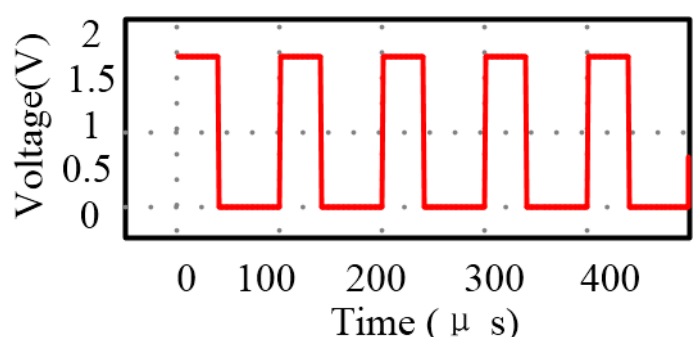

(b)

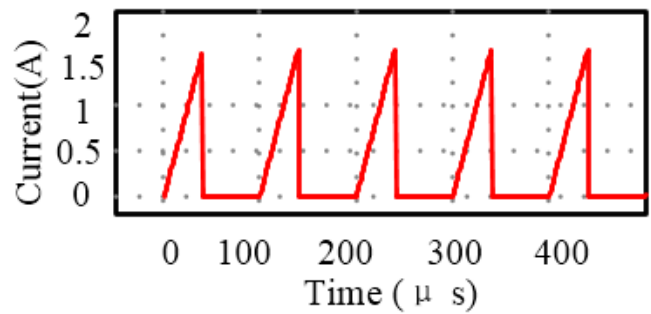

(d)

Figure 13. The comparison of $i_{L 1}$. (a) pulse-width modulation (PWM) in the experiment. (b) PWM in the simulation. (c) $i_{L 1}$ in the experiment. (d) $i_{L 1}$ in the simulation.

\section{Conclusions}

In this paper, a novel inductor-based non-dissipative equalizer (NIBNDE) is proposed. The structure of the NIBNDE, the equalization principle, theoretical analysis and performance comparisons with other equalizers are presented. The simulations show that, compared to the SSIE, the NIBNDE reduces the balancing time by $29.23 \%$ in four cells, $34.52 \%$ in six cells and $22.4 \%$ in sixteen cells, respectively. Compared to the PAE, the NIBNDE can greatly reduce the number of energy storage elements, especially when there are a large number of batteries in series. The experimental results verify the conclusion of the simulation and the equalization accuracy of the NIBNDE. In summary, the NIBNDE can reduce the number of energy storage elements while retaining a good equalization speed. Future research will focus on using the state of charge as an index of inconsistency to achieve higher precision of the proposed circuit.

Author Contributions: Conceptualization, C.L. and L.K.; Data curation, S.W.; Formal analysis, C.L. and L.K.; Funding acquisition, L.K.; Investigation, S.W.; Methodology, C.L. and L.K.; Project administration, L.K.; Resources, L.K.; Software, Z.W. and H.R.; Writing—original draft, C.L.; Writing一review and editing, S.W., Z.W. and H.R.

Funding: This research was funded by Science and Technology Development Special Foundation of Guangdong, China (2017B010120001). 
Acknowledgments: I would like to express my sincere gratitude to my supervisor, Longyun Kang, who has given me a lot of effective advice during the experiments and the paper-writing. I would also like to thank the anonymous reviewers for dedicating the time to review my paper despite their busy schedules.

Conflicts of Interest: The authors declare no conflict of interest.

\section{References}

1. Wang, S.; Kang, L.; Guo, X.; Wang, Z.; Liu, M. A Novel Layered Bidirectional Equalizer Based on a Buck-Boost Converter for Series-Connected Battery Strings. Energies 2017, 10, 1011. [CrossRef]

2. Ye, Y.; Cheng, K.W.E.; Fong, Y.C.; Xue, X.; Lin, J. Topology, Modeling, and Design of Switched-Capacitor-Based Cell Balancing Systems and Their Balancing Exploration. IEEE Trans. Power Electron. 2017, 32, 4444-4454. [CrossRef]

3. Yuanmao, Y.; Cheng, K.W.E.; Yeung, Y.P.B. Zero-Current Switching Switched-Capacitor Zero-Voltage-Gap Automatic Equalization System for Series Battery String. IEEE Trans. Power Electron. 2012, 27, 3234-3242. [CrossRef]

4. Han, W.; Zhang, L.; Han, Y. Mathematical modeling, performance analysis and control of battery equalization systems: Review and recent developments. In Advances in Battery Manufacturing, Services, and Management Systems; Li, J.S., Zhou, S.Y., Han, Y.H., Eds.; Wiley-IEEE Press: Hoboken, NJ, USA, 2017; p. 416, ISBN 9781119060741.

5. Yarlagadda, S.; Hartley, T.T.; Husain, I. A Battery Management System Using an Active Charge Equalization Technique Based on a DC/DC Converter Topology. IEEE Trans. Ind. Appl. 2013, 49, 2720-2729. [CrossRef]

6. Kirshenboim, O.; Peretz, M.M.; Zeltser, I. Non-isolated parallel balancing converter for serially connected batteries string. In Proceedings of the IEEE Applied Power Electronics Conference and Exposition (APEC), Tampa, FL, USA, 26-30 March 2017; pp. 1236-1241.

7. Dong, B.; Li, Y.; Han, Y. Parallel Architecture for Battery Charge Equalization. IEEE Trans. Power Electron. 2015, 30, 4906-4913. [CrossRef]

8. Phung, T.H.; Collet, A.; Crebier, J. An Optimized Topology for Next-to-Next Balancing of Series-Connected Lithium-ion Cells. IEEE Trans. Power Electron. 2014, 29, 4603-4613. [CrossRef]

9. Kutkut, N.H. Nondissipative current diverter using a centralized multi-winding transformer. In Proceedings of the IEEE Power Electronics Specialists Conference (PESC), Saint Louis, MO, USA, 22-27 June 1997; pp. 648-654.

10. Baughman, A.C.; Ferdowsi, M. Double-Tiered Switched-Capacitor Battery Charge Equalization Technique. IEEE Trans. Ind. Electron. 2008, 55, 2277-2285. [CrossRef]

11. Hisashi, F. Balancing Circuit of Energy Element. JP2010220373A. 30 September 2010.

12. Zeyuan, L.; Shang, Y.; Bin, D.; Zhang, C. A pack-to-cell-to-pack battery equalizer with soft-switching based on buck-boost and bidirectional LC resonant converters. In Proceedings of the IEEE Energy Conversion Congress and Exposition (ECCE), Milwaukee, WI, USA, 18-22 September 2016; pp. 1-7.

13. Li, W.; Liao, X.; Gao, Z. A modular equalizer using buck/boost converters with snubber capacitors for series-connected supercapacitors. In Proceedings of the IEEE International Conference on Industrial Technology (ICIT), Taipei, Taiwan, 14-17 March 2016; pp. 1904-1909.

14. Zhou, Z.; Shang, Y.; Duan, B.; Zhang, C. An Any-Cell(s)-to-Any-Cell(s) Equalizer Based on Bidirectional Inductor Converters for Series Connected Battery String. In Proceedings of the IEEE 11th Conference on Industrial Electronics and Applications (ICIEA), Hefei, China, 5-7 June 2016; pp. 2511-2515.

15. Chen, Y.; Liu, X.; Cui, Y.; Zou, J.; Yang, S. A Multi-winding Transformer Cell-to-Cell Active Equalization Method for Lithium-Ion Batteries with Reduced Number of Driving Circuits. IEEE Trans. Power Electron. 2016, 31, 4916-4929. [CrossRef]

16. Liu, J.; Xu, M.; Zeng, J.; Wu, J.; Kai Wai Eric, C. Modified voltage equaliser based on Cockcroft-Walton voltage multipliers for series-connected supercapacitors. IET Electr. Syst. Transp. 2018, 8, 44-51. [CrossRef]

17. Li, S.; Mi, C.C.; Zhang, M. A High-Efficiency Active Battery-Balancing Circuit Using Multiwinding Transformer. IEEE Trans. Ind. Appl. 2013, 49, 198-207. [CrossRef]

18. Liu, J.; Wu, J.; Zeng, J.; Guo, H. A Novel Nine-Level Inverter Employing One Voltage Source and Reduced Components as High-Frequency AC Power Source. IEEE Trans. Power Electron. 2017, 32, 2939-2947. [CrossRef] 
19. Guo, X.; Kang, L.; Huang, Z.; Yao, Y.; Yang, H. Research on a Novel Power Inductor-Based Bidirectional Lossless Equalization Circuit for Series-Connected Battery Packs. Energies 2015, 8, 5555-5576. [CrossRef]

20. Han, W.; Zou, C.; Zhou, C.; Zhang, L. Estimation of Cell SOC Evolution and System Performance in Module-based Battery Charge Equalization Systems. IEEE Trans. Smart Grid 2018. [CrossRef]

21. Li, W.; Kang, L.; Guo, X.; Yao, Y. Multi-Objective Predictive Balancing Control of Battery Packs Based on Predictive Current. Energies 2016, 9, 298. [CrossRef]

22. Han, W.; Zhang, L.; Han, Y. Computationally efficient methods for state of charge approximation and performance measure calculation in series-connected battery equalization systems. J. Power Sources 2015, 286, 145-158. [CrossRef]

(C) 2018 by the authors. Licensee MDPI, Basel, Switzerland. This article is an open access article distributed under the terms and conditions of the Creative Commons Attribution (CC BY) license (http:/ / creativecommons.org/licenses/by/4.0/). 